\title{
Correction to: An LES for the Effects of Particle Size and Velocity Ratio on the Flow Structure in the Secondary Combustor
}

\author{
Jong-Chan $\mathrm{Kim}^{1}{ }^{1} \cdot$ Hanyoung $\mathrm{Choi}^{1} \cdot$ Hong-Gye Sung ${ }^{1}$ \\ Published online: 4 January 2021 \\ (c) The Korean Society for Aeronautical \& Space Sciences 2020

\section{Correction to: \\ International Journal of Aeronautical and Space Sciences \\ https://doi.org/10.1007/s42405-020-00305-3}

Due to an unfortunate oversight the acknowledgment section has been omitted. It should be read:

Acknowledgements This work was supported by the National Research Foundation of Korea (NRF) grant funded by the Korea government (MEST) (No. 2019R1A2C1009253) and Brain Korea 21 Four (BK21, 5199990714521) grant funded by the Korea government.

Publisher's Note Springer Nature remains neutral with regard to jurisdictional claims in published maps and institutional affiliations.

The original article can be found online at https://doi.org/10.1007/s42 405-020-00305-3.

\footnotetext{
Hong-Gye Sung

hgsung@kau.ac.kr

Jong-Chan Kim

jckim1201@kau.kr

Hanyoung Choi

chy0314@kau.kr

1 Korea Aerospace University, Goyang 10540, Gyeonggi,

Korea
} 